\title{
The Role of Leadership in Achieving Sustainable Organizational Change and the Main Approaches of Leadership during Organizational Change
}

\author{
Jeton Zogjani, M.Sc \\ zogjanijeton@gmail.com
}

Samed Raçi, M.Sc

samed.raci@gmail.com

Doi:10.5901/ajis.2015.v4n3p65

\begin{abstract}
In this research paper is analysed the role of leadership in organizational change and is identify the main approaches that leaders implement during organizational change. The leadership role in process of organizational change is very necessary and the responsibility of leadership is due of continuous development of organizational environment and evolutions of internal and external environments in organizational change. The process of change is associated with different difficulties and during process of change, leadership is challenged from these difficulties and in same time they have to create sustainable organizational change through their authority in decision making, experiences, educations and interpersonal relation within organization. In process of change, leadership has different approaches and in this research paper is used effective approach of leadership and transformational leadership approaches. Then, as main objectives that are defined in this research papers, are as following: What is the main features and challenges in process of change? Which is the role of leadership in organizational change? What is the impact of leadership toward outside development and ethical behaviour in process of change? Which are the main actions that leaders need to have in process of change? Which are the main approaches of leadership in process of change?
\end{abstract}

Keywords: effective approach, interpersonal relations, suitability change, transforming approach

\section{Introduction}

In our modern times, the different processes in organizational change in all organizations / businesses have become very essential. All this comes as a result of the competition in the global market but to achieve this level everyone must try to create an approach in leadership, as stated by Iqbal et al (2012). This is a necessity to create sustainability in organizational change from leaderships' side. That is the main reason that we must understand that leadership as a process that affects its subordinates, whose purpose is to achieve its desired results, Jong \& Hartog (2007). We must have knowledge on authority, actions, behaviours and motives that these individuals have and that these attributes affect the efforts to realize the goals in organizational changes and also his group in the organization. Then, the leader tries to identify the processes that lead to change, the capabilities and qualities in the group of people that he leads, then which assist the leader in pushing forward the processes towards creating sustainability and organizational change, Scot et al (2008). In second part are identified two leadership approaches in process of organizational change. The first one is effective approach; it requires long-term support and implications of leaders in developing people in organizational change, Bolden (2010). The second is transformational leadership approach and their aim is changes and transforms individuals within organization (or to change their interpersonal behaviour in organization), in other context it is ability that transformational leadership want to get by people in organization to change and to improve their behaviour, Hall et al (2008)

\section{Literature Review}

To analyze the way that leadership aims to achieve sustainability in organizational change, we must look at the role and responsibilities of leadership during the processes of change. According to By (2005), change is a feature present in the organizational life, in the operational side and the strategic one, so organizational change is a challenge for each participant in the changing process. As emphases by Gill (2003), the process of change to be successful in any 
organization should be well managed by leaders through planning, organizing, controlling and personnel or otherwise we will have a failed process of change as shown by the experience of numerous researches on organizational changes. Because of the high dynamic of change in all organizations / businesses, the leaders who lead to change are a primary need for organizational management. Since above was discussed on the definition of leadership, its role and the sustainability of organizational change then we need to further discuss two issues; first the role of the leader towards achieving sustainability of organizational changes and second defining the two different approaches to leadership.

\subsection{The role of leadership in sustainability of organizational change}

Originally leadership has a long history of development so as cited by Day (2011) leadership has developed into three main contexts: conceptual, practical and research. The main reason of such contexts has been the relationship between the practical and scientific sides in developing leadership and to show the necessity of human and social capital that operate within the organization. During this whole time of development the inner structure in organizations has been built on structure and hierarchy, including its decision making power in the organization. Also, on the other hand as proposed by Arvey et al (2006) \& Kellaway (2002), leadership is totally under the influence of development. So while we have the role of leadership as an important factor within the organization (decision making, group and capital) to create sustainability to the processes of organizational changes, there is also the role of leadership towards outside developments, and this is reasoned by the fact that the change of the external environment can affect the organizational changes and what remains is that leadership tries to adapt to these changes. Naturally this depends on the ability, level of qualities and performance of the leaders to overcome these organizational changes from the present in the future.

One of the possibilities of leadership to create stability during the process of change is the use of ethical values of a leader within an organization. As argued by Burnes \& By (2012), if leaders decide to apply ethical approach which is compatible with all the participating parties in the organization and not only their only needs, then this would create a real possibility for sustainable and successful change in an organization. So, when an organization has a sustainable level of leadership ethics, this creates the possibility to achieve positive changes. As proposed by Svenson \& Wood (2007) when the ethical behaviour of the leadership is in accordance with the goals of creating stability and sustainability in the process of organizational change. Often in critical periods of changes that challenge different organizations, the behaviour and ethics of the leadership is a crucial element to pass this process successfully. In case the opposite happens and the leadership tries to take advantage in a non ethical way on the group (interpersonal relations) in the organization, then these actions seriously affect the possibility of adapting to changes and the sustainability along the process of changes in the organization.

However, the creation of stability during organizational changes could be the behaviour that the leadership applies to its employees or the interpersonal relations in the organization. As argued by Jong \& Hartog (2007), if the leaders allow the groups behaviours in the organizational changes to be open (freedom in their actions), this will offer productivity in services and the improvement in the work process from the innovative knowledge that the group offers in organization, while the result of this would be an increased performance and sustainability to the changes in the organization. Also, if we look at the role and responsibility those leaders have towards change, their contribution is huge both in the process of changes and in the approach to identify and solve the problems in organizational changes. Various studies along the process of sustainability in organizational changes have emphasized the necessary actions of the leadership in the process of changes. According by Higgs \& Roland (2005), these various organizational actions are to identify the need for change, the definition of the structure for change, implementation of change and control and effective development of the whole process.

If we look at today's change environment in organizations, the goal of the leader is to offer solution to the problems in the organization and to incorporate his activities in the realization of the process of changes in the organization. This contains in itself two essential actions of leadership: on one side there is the need for change that could be identified through these actors: total change of the organization, need of the group (interpersonal relations) for changes, different outside pressures that make the organization need internal changes and the lack of organizational change stability, Hawkings \& Dulewicz (2009). And on the other side there is change as a potential to reach success in competition and sustainability in organizational changes and this could be achieve through innovations and the contribution of all participants in this process, Randal \& Coakley (2007). Also, the necessary resources should not be excluded, therefore as emphasized by Gill (2003), the lack of these resources such as budget, time, knowledge and experience, policies of organizational change, etc; during the efforts to reach to changes often remains a failure.

Since the process of change can often be difficult and unstable because of different factors such as: environment, 
development of modern technology, growth of global competition, an increasing level of demographical changes of work force, etc reflect in the increased role of leadership in modern times. Transformation and sustainability of organizational change remain in their focus and this means that the leaders are the crucial element in creating sustainability during the process of organizational change, Eisenbach (1999). But if we consider the initiatives of organizations / businesses that make an effort towards realizing their organizational strategies during the process of change, there are still a large number of these organizations (70\% - 80\%) that fail, Lyons et al. (2009). It remains a challenge for leadership which aims the management of the process of change when organizations / businesses are in the stage of transformation and the creation of the sustainability of organizational changes. At the same time it remains the only way of this process which requires the support of the leadership-it to change in this delicate phase of organizational change.

In different organizations the role of leadership to create stability during the process of changes often varies on the quality of attributes their leaders have, and the leaders who own these attributes play an important role in organizational change, as well as these attributes enable organizational stability for the years ahead, Denton \& Vloebergs (2003). The future is quite challenging and unsure from the possible organizational changes which are continuous but it is very important to possess organizational advantages. This can be reached in organizations where the leader and his group have knowledge, skills and quality. When the organization has the above mentioned qualities, it is easier to adapt and transform into a new organizational environment. When leadership in an organization is of this level, then they need to apply and develop methods of organizational change which must be sustainable during the whole process.

\subsection{The effective approach of leadership vs. the transforming leadership approach}

In the second part of research paper, will discussed about two approaches of leadership during organizational changes. During different time periods of development and organization in general, the implementation of these approaches has been necessary, Ramosaj (2008). After this, we need to identify the two leadership approaches that act on organizational changes. The first approach defines the effective approach of leadership, and each leader who aims at being an effective leader must own these personal characteristics such as: respect, trust and action, Karp (2013). Authors like Brewer (2000) \& Choonhaklai \& Singsuriya (2008), have defined the effectiveness of leadership as a key factor of success or failure in an organization. When external changes reflect internal organizational changes, it is the leadership's responsibility to effectively manage these challenges. On the other hand, effective leadership needs to support the group with motivation, understanding their needs, etc; which leads to the development of leaders in "internal" organization, Riggio \& Reichard (2008).

To create effective leadership behaviour, the leader must accomplish his responsibilities successfully towards organizational changes, where there are two primary behaviours that belong to an effective leader: first he defines the orientation of the leader to his obligations and second his orientation towards the relation between the leader and his group, Boesman (2008). Effective leadership must continuously respond to the unforeseen challenges such as: possible threats, the tendency of organizational change, open to technological innovation and continuously ready to motivate the group in the organization towards productivity growth and realization of goals in the organization, Wiley (2010). Also, this approach has come as a result of continuous challenges that organizations / businesses face and also because of their inability to adapt to organizational change. For this reason leaders must create a leadership relationship and organizational culture so they can increase their performance during these organizational changes, Choonhaklai \& Singsuriya (2008). If this approach to leadership is successful, this would create an effective sustainability in organizational changes, and the opposite would be total failure of the organizational change system.

Now we must focus on the second approach of leadership, where the transforming leadership will be discussed. This approach has been discussed by many authors and researchers of leadership so as defined by Broome \& Hughes (2004) transformational leaders offer their faith to the group to increase self-confidence and conviction of the group to change processes. Then, as described by Jun (2006), this approach describes how a leader is transformed from one situation to the other. According to Svensson (2005) this approach has in its core the identification of specific situations of leadership. These leaders present this leadership approach as a transformational need, which continuously requires creativity, so based on their abilities they pretend to know the future which cannot be known in the present, as referred by Strategic Direction (2011). This approach is typical for those leaders whose vision is the development of different dynamic organizational changes and according to Ruddell (2008) the approach of the transforming leadership is one of the most favourites during this century.

This approach of transforming leadership has used also the collaborative abilities of the leader during the organizational challenges, which would reflect not only in the internal change of sustainability creation but also in 
strengthening the organizational changes, Maddock (2011). Actually the way the transforming leadership approach works is totally through the creation of an organizational vision by strengthening the role of the group (interpersonal relations) in organizational changes and then building the action strategy. As argued by Mehmood \& Arif (2011) all this is done to accomplish the organizational change. Also, according to this approach leaderships aims at continuously increasing the effectiveness of the group by engaging them both in vision and in organizational development, De Poel (2012). If we consider the development of the group and their behaviour according to this approach, these leaders are focused so that each member reaches his productivity through faith and his intentions towards the final goal of the organization. This must be reflected as a positive change of the organization but the greatest contribute in this "work commitment" belongs to the transforming leadership, Riaz et al (2012).

Above was analyzed this type of leadership approach and his organizational group, where their relations are closely related for the collective purpose of organizations but the main factor of this successful transformation belongs to the leadership's changes. So, based on this approach to ensure sustainable and competitive organizational changes, the leaders must make decisions, Singh \& Krishnan (2005). If we examine the literatures of this approach we will understand that transformational leadership in collaboration with its organizational group will give leadership the opportunity to advance and get to the organizational sustainability which includes in itself a high level of motivation. Despite its role in terms of solving organizational problems, this approach also includes an institutional development and organizational changes, which has as a fundamental basis the achievement of goals, Love et al. (2009).

\section{Methodology}

In this part of research paper is described the method and approaches that are used. All the arguments that are used in this research paper are based mostly on journals, books and different literature from different authors of leadership and organizational change. It means that we have used qualitative research methods and deductive approaches. As indicated by (Becker 1996), the qualitative research method is not presented by numbers rather it is focused on meaning and involved of the researcher in the process. Then, through deductive approaches we have developed our hypothesis for role of leadership and their main approaches, based on existing theory and other source (that are mentioned above).

\section{Conclusion}

In the conclusion part of this paper is defined that the role of leadership in creating stability during organizational changes is very important. This is reasoned by the fact that many authors of the leadership area have commented that the number of organizations/businesses that are not capable of creating stability during organizational changes is quite high. This comes as a result of the factors discussed on the first part of this paper, where only the role of leaders is not enough compared to the challenges of change. So, in the first part we have analyzed the role of leadership to achieve sustainability during organizational changes which comes through the influence of circumstances during organizational change, ethical behaviour and the relationship of the leaders towards the group, lack of experience towards changes, identification of the need for internal organizational changes. So here we have the internal organizational environment which sets organizational stability of change. On the other hand there is the internal environment that could affect the stability of organizational changes through factors such as: high dynamics of organizational change in general, technology, competition, etc. So, both internal changes and external are leadership's challenge to create consistency throughout the process of change.

The second part of this paper is dedicated to the identification of two's Leadership approaches that find their application in the field of leadership; one is defined as the effective approach and the other as transformational leadership's approach. The role of leadership according to the effective approach is the level of harmonization that effective leadership tries to achieve through its action style and circumstances that change the environment. According to this approach effective leadership is when the company adapts to different situations of organizational change through respect, trust and action. Since often there are internal and external organizational changes, then according to this approach effective management, motivation and inspiration of the organizational group is needed. All of these effective measures of the leaders serve to challenge changes with the highest effectiveness possible. According to this approach, when the leadership aims a high level of effectiveness then collaboration between the leadership and organizational culture is needed.

As a second approach, on this paper is defined the transformational leadership which at its core contains charisma and individual sensitivity that these leaders have towards organizational change. Then, these leaders aim at the 
realization of organizational goals through their vision, organizational group empowerment and action strategy. Transformational leadership is one of the mostly used approaches in our modern times. This high dynamics of today's organizational change, their visionary and transformational nature make the leader able to challenge the environmental changes with their leader's charisma. Also, leadership's commitment under this approach is the engagement of the organizational group, through different factors which could affect the growth of group motivation and organizational development. This will give its effects on productivity growth.

\section{References}

Arvey, R. D. et al. (2006). The determinants of leadership role occupancy: genetic and personality factors. The Leadership Quarterly. 17. pp. $1-20$

Becker, H.S. (1996). The epistemology of quantitative research. In R. Jessor, A. Colby, \& R. A. Shweder

Boesman, G. (2008). Effective Leadership in a changing world. Journal of Financial Service Professional. 62 (3) pp. 36 - 38

Bolden, R. (2010). Leadership, Management and Organisational Development, Centre for Leadership Studies, UK, pp. 1 - 12

Broome, G. H. \& Hughes, R. L. (2004). Leadership Development: past, present, and future. Human Resource Planning. 27 (1) pp. 24 32

Burnes, B. \& By, T. B. (2012). Leadership and change: the case for greater ethical clarity. Journal of Business Ethics. 108 (2) p. 239 252

By, T. B. (2005). Organizational change management: A critical review. Journal of Change Management. 5 (4) pp. 369 - 380

Choonhaklai, S. \& Singsuriya, P. (2008). Thailand's approach to achieving effective leadership: culture and outcomes. International Employment Relation Review. 14 (2) pp. 38 - 55

Day, D. D. (2001). Leadership development: a review context. The Pennsylvania State University. University Park. The Leadership Quarterly. 11 (4) pp. 581 - 613

De Poel, F. M. et al (2012). Climate control? The relationship between leadership climate for change, and work outcomes. The International Journal of Human Resource Management. 23 (4) pp. 694 - 713

Denton, M \& Vloeberghs, D. (2003). Leadership challenges for organization in the New South Africa. Leadership and Organizational Development Journal. 24 (2) pp. 84 - 95

Eisenbach, R. et al (1999). Transformational leadership in the context of organizational change. Journal of Organizational Change Management. 12 (2) pp. 80 - 89

Gill, R. (2003). Change management - or change leadership? Journal of Change Management. 3 (4) pp. 307 - 318

Hall et al (2008). Transformational Leadership: the Transformation of Managers and Associates, University of Florida, no. HR020, pp. 1 3

Hawkins, J. \& Dulewicz, V., (2009). Relationships between leadership styles, the degree of change experienced, performance and follower commitment in policing. Journal of Change Management. 9 (3) pp. 251 - 270

Higgs, M. \& Rowland, D. (2005). All change great and small: Exploring approaches to change and its leadership. Journal of Change Management. 5 (2) pp. 121 - 151

Iqbal, J. et al. (2012). Leadership styles: Identifying approaches and dimensions of leaders. Interdisciplinary Journal of Contemporary Research in Business, 4 (3) pp. 1 - 20

Jong, J. P. J. \& Hartog, D.N.D. (2007). How leaders influence employees innovative behaviour. European Journal of Innovation Management, 10 (1) pp. 41 - 64

Jun, J. et al. (2006). The forgotten follower: a contingency model of leadership and follower self-leadership. Journal of Managerial Psychology. 21 (4) pp. 374 - 388

Karp, T. (2013). Developing oneself as a leader. Journal of Management Development. 32 (1) pp. 127 - 140

Love, D. et al. (2009). Transformational leadership, campus, climate and its impact on student retention. Allied Academies International Conference: Proceedings of the Academy of Educational Leadership. 14 (1) pp. 31 - 36

Lyons, J. B. et al. (2009). The impact of leadership on change readiness in the US Military. Journal of Change Management. 9 (4) pp. 459 - 475

Maddock, S. (2011). Transformational public leadership is collaborative: Governments and public services have to change. Human Resource Management International Digest. 19 (7) pp. 40 - 41

Mehmood, Z. I. \& Arif, M. I. (2011). Leadership and HRM: Evaluating new leadership styles for effective human resource management. International Journal of Business and Social Science. 2 (15) pp. 236 - 243

Ramosaj, B. (2006). Management: Creative Management \& Leadership. 1st ed. (ISBN 9951-441-17-3) Pristine: KGT

Randal, L. M. \& Coakley, L. A., (2007). Applying adaptive leadership to successful change initiatives in academia. Leadership and Organizational Development Journal. 28 (4) pp. 325 - 335

Riaz et al (2012). Transformational leadership and employees' career salience: an empirical study conducted on banks of Pakistan. International Journal of Business and Social Science. 3(8) pp. 153 - 160

Riggio, R. E. \& Reichard, R. J. (2008). The emotional and social intelligence of effective leadership: An emotional and social skill approach. Journal of Managerial Psychology. 23 (2) pp. 169 - 185

Ruddell, L. S. (2008). Transformational Leadership as a effective classroom leadership model for business ethics instruction. Academy 
of Educational Leadership Journal. 12 (2) pp. 49 - 68

Scot, G. et al (2008). Learning leader in time of change. Academic Leadership Capabilities for Australian Higher Education. Australian Council for Educational Research. pp. 1 - 173

Singh, N. \& Krishnan. V. R. (2005). Towards understanding transformational leadership in India: a grounded theory approach. The Journal of Business Perspective. 9 (2) pp. 5 - 17

Strategic Direction (2011). Transforming leadership for success and sustainability: Leading today's industries into the future. Strategic Direction (ISSN: 0258 - 0543). 27 (3). pp. 19 -21

Svenson, G. \& Wood, G. (2007). Sustainable leadership ethics: a continuous and iterative process. Journal and Organizational Development Journal. 28 (3). pp. 251 - 268

Svensson, G. (2005). Leadership performance in TQM: a contingency approach. The TQM Magazine, 17 (6). pp. 527 - 536

Wiley, J. W. (2010). The impact of effective leadership on employee engagement. Employment Relation Today. 37 (2). pp. 47 - 52 